\title{
A PREVENÇÃO DOS RISCOS EM ATIVIDADES MINERÁRIAS: ANÁLISE DA INSUFICIÊNCIA ESTATAL NA CONCESSÃO DO LICENCIAMENTO AMBIENTAL APLICADA AO CASO DE MARIANA - MG
}

\author{
PREVENTION OF RISKS IN MINING ACTIVITIES: \\ ANALYSIS OF STATE INSUFFICIENCY IN THE GRANT OF \\ ENVIRONMENTAL LICENSING APPLIED TO THE CASE OF MARIANA - MG
}

\section{Lais Aparecida Maciel Duarte', Márcio de Souza Bernardes² e Francielle Benini Agne Tybusch ${ }^{3}$}

\section{RESUMO}

O licenciamento ambiental, revestido de seu caráter preventivo, tem por objetivo assegurar a tutela ambiental do meio ambiente, bem como de maneira direta e indireta proteger os Direitos Fundamentais Humanos. Entretanto a prática demonstra na mineração diversos acidentes com barragens de rejeitos, barragens estas que necessariamente passaram por processos de licenciamento ambiental. O presente trabalho analisará o processo de licenciamento ambiental realizado na barragem de Fundão, em Mariana - MG e sua possível contribuição para o desastre ocorrido o dia 05 de novembro de 2015. Como metodologia se utilizou do método de abordagem dedutivo; como técnicas de pesquisa, a documentação indireta, pois a pesquisa teve como fonte livros, revistas jurídicas, artigos científicos e legislação pertinente. Assim, o trabalho concluiu que o procedimento da licitação necessita de um novo marco principiológico no setor público que o gerencia, objetivando evitar ao máximo a ocorrência de desastres para que efetivamente os princípios protecionistas e preventivos sejam efetivamente colocados em prática.

Palavras-chave: Licenciamento Ambiental, Danos Socioambientais, Barragens de Rejeito, Meio Ambiente, Mariana- MG.

\section{ABSTRACT}

The environmental licensing, covered by its preventive character, aims to ensure the environmental protection of the environment, as well as directly and indirectly protecting Fundamental Human Rights. However, practice demonstrates in mining several accidents with tailings dams, dams that necessarily went through environmental licensing processes. This work will analyze the environmental licensing process carried out in the Fundão dam, in Mariana - MG and its possible contribution to the disaster that occurred on November 5, 2015. As a methodology, the deductive approach method was used; as research techniques were indirect documentation was used, as the source of the research was books, legal journals, scientific articles and pertinent legislation. Thus, the work concluded that the bidding procedure needs a new principle framework in the public sector that manages it, aiming to avoid as much as possible the occurrence of disasters so that the protectionist and preventive principles are effectively put into practice.

Keywords: Environmental Licensing, Socio-environmental Damage, Tailings Dams, Environment, Mariana- MG.

1 Discente do Curso de Direito na Universidade Franciscana. E-mail: lais_ap99@hotmail.com

2 Doutorado em Direito pela Universidade Federal de Santa Catarina - UFSC (2017), Mestrado em Direito pela Universidade de Santa Cruz do Sul - UNISC (2005), Especialista em Direito Processual Civil pela Universidade Lutherana do Brasil ULBRA (2003), Bacharel em Direito pela Universidade Federal de Santa Maria - UFSM (2000). Professor do Curso de Direito da Universidade Franciscana - UFN. Advogado. E-mail: msbernardes@hotmail.com

3 Doutora em Direito pela Universidade do Vale do Rio dos Sinos - UNISINOS. Mestre em Direito pela Universidade Federal de Santa Maria - UFSM com bolsa da Fundação de Amparo à Pesquisa do Estado do Rio Grande do Sul, FAPERGS. Bacharel em Direito pela Faculdade Palotina de Santa Maria - FAPAS. Professora do Curso de Direito da Universidade Franciscana UFN. Coordenadora do Laboratório de Extensão da Universidade Franciscana - UFN. E-mail: francielleagne@gmail.com 


\section{INTRODUÇÃO}

O presente trabalho tem por objetivo estudar o procedimento do licenciamento ambiental, bem como sua condução no desastre ocorrido com a barragem de Fundão em Mariana - MG. Para tanto será tratado o caráter preventivo que possui o licenciamento ambiental e analisar-se-á, por meio de estudo da legislação brasileira que define o trâmite do licenciamento ambiental, se este pode ou não ter contribuído para a ocorrência do evento na barragem de Fundão.

O estudo tem como questionamento: No caso Mariana - MG é possível alegar a possibilidade da insuficiência estatal na concessão do licenciamento frente ao rompimento ocorrido em 05 de novembro de 2015? Pretende-se, a partir da análise da legislação ambiental e das normas técnicas do licenciamento ambiental, verificar o caso específico de Mariana e os seus impasses no que se refere à efetiva prevenção dos desastres e a eficácia das normas ambientais aplicadas ao processo de licenciamento da barragem de Mariana - MG. Haverá, ademais, o estudo de caso referente ao evento ocorrido com a barragem de rejeitos de Fundão - MG, examinando seus aspectos quanto ao processo de licenciamento ocorrido na barragem.

Para tanto se utilizou do método de abordagem dedutivo, a partir da leitura da legislação ambiental e posições doutrinárias no campo do direito ambiental, bem como da observação de ocorrências de rompimento de barragens e seus respectivos processos de licenciamentos. As técnicas de pesquisa utilizadas foram a de documentação indireta, pois a pesquisa teve como fonte livros, revistas jurídicas, artigos científicos e legislação pertinente. Dessa maneira, serão utilizados meios bibliográficos e documentais sob a óptica da legislação e doutrina correlatas relacionada ao direito ambiental, comparada com o licenciamento desenvolvido na barragem de Fundão - MG.

O primeiro capítulo teve por base como escopo a analise das formas de prevenção dos riscos ambientais existentes no Brasil, todas calcadas no princípio da prevenção ambiental. Nele é demonstrado a aplicação do licenciamento ambiental e dos estudos de impactos ambientais como instrumentos da política ambiental brasileira.Já no segundo capítulo, foi necessário demonstrar um pouco mais acerca dos danos decorridos do rompimento da barragem de Fundão. Foram abordados os danos sociais, econômicos e ambientais que ocorreram nas cidades a jusante da barragem de Fundão, bem como os ocorridos em cidades e populações que dependiam do rio Doce, mas não foram atingidas diretamente.

Por fim, na terceira parte do texto, buscou-se a conexão entre os dois primeiros capítulos, através da análise das possibilidades de o procedimento de licenciamento ambiental ter sido um dos motivos pelos quais ocorrera a tragédia ambiental em Mariana - MG. Nesse capítulo, buscou-se, assim, analisar o iter procedimental do licenciamento ambiental realizado na barragem de Fundão e sua conformidade ou desconformidade com a legislação ambiental. 
A PREVENÇÃO DOS RISCOS AMBIENTAIS NO BRASIL: UM ESTUDO SOBRE O PROCESSO DE LICENCIAMENTO AMBIENTAL

Todos os seres vivos, desde o início de suas existências na terra interagem com o meio em que estão inseridos, modificando-o e transformando-o de acordo com suas necessidades (BASTOS; FREITAS, 2006, p. 18), dessa maneira, o meio ambiente e os seres humanos interagem a todo o momento, e os seus reflexos se propagam por todas as sociedades, em razão de seu caráter transfronteiriço.

A problemática ambiental após o século XX foi mais frequentemente debatida, considerando a finitude e limitação dos bens naturais e a dependência intrínseca entre o meio ambiente e o ser humano. Entretanto, conforme explica Niencheski (2017, p. 184), “a preocupação com o esgotamento dos bens naturais, renováveis e não renováveis, era entendida, principalmente pelos países emergentes, como antinômicas ao desenvolvimento". Diante desse cenário, muitos países não se debruçaram, eficientemente, na proteção ambiental que se fazia necessária, mantendo a sustentabilidade e o desenvolvimento econômicos como dois objetivos antagônicos.

Nesse período, foram realizados diversos eventos pelo mundo que trataram sobre os problemas enfrentados pelas mais diversas nações relacionadas à degradação ambiental existente no mundo. O Brasil sempre esteve presente nesses eventos ${ }^{4}$, inclusive sediando dois importantes deles. Contudo, conforme asseveram Campos e Muchagata (2017, p. 39), apesar de o Brasil assumir compromissos em âmbito nacional e até revelar-se expoente em proteção ambiental, os avanços reais na proteção socioambiental do país deixam a desejar.

A lei 6.938/81 conceitua meio ambiente como sendo: "o conjunto de condições, leis, influências e interações de ordem física, química e biológica, que permite, abriga e rege a vida em todas as suas formas" (BRASIL, 1981). Assim sendo, conclui-se que o meio ambiente interage e influi sinergicamente com múltiplos aspectos da vida e do próprio meio ambiente em si, haja vista ser um sistema complexo. Nas palavras de Antunes (2019, p. 03), “o Direito Ambiental é, portanto, a norma que, baseada no fato ambiental e no valor ético ambiental, estabelece os mecanismos normativos capazes de disciplinar as atividades humanas em relação ao meio ambiente".

É inegável a convergência entre o direito ambiental e os Direitos Humanos, à medida que assegurar um padrão de vida sadio e com qualidade, não só às atuais, mas às futuras gerações, implica em assegurar padrão de vida digno, relacionando-se, assim, com a capacidade de usufruir dos direitos humanos, entre eles a tutela do direito à vida.

Um dos maiores entraves na tutela ambiental, diz respeito ao valor econômico atribuído aos bens protegidos pelo direito ambiental. Deste modo, ainda está presente, em grande parte da sistemática mundial, principalmente na brasileira, uma visão totalmente antropocêntrica, resultando em 4 A exemplo: "Realizada no Rio de Janeiro, em 1992, a "Cúpula da Terra", como ficou conhecida, adotou a "Agenda 21', um diagrama para a proteção do nosso planeta e seu desenvolvimento sustentável, a culminação de duas décadas de trabalho que se iniciou em Estocolmo em 1972" (ONU, 2020). 
um meio ambiente tratado superficialmente, vez que, ainda nos dias atuais, podem ser vistas práticas pouco sustentáveis e preservacionistas. Tem-se, no Brasil, um conjunto de leis visando à proteção dos bens naturais bem como uma utilização mais racional desses, contudo parece estar esquecida a necessidade de sua efetivação.

Muitas dessas práticas podem ser associadas com a presença de um sistema capitalista extrativista que visam o lucro acima da proteção ambiental e, (in) diretamente do bem estar populacional. Conforme Cruz e Bodnar (2012, p. 112), a insustentabilidade do modelo de produção e consumo capitalista coloca em risco o futuro da humanidade, riscos esses que podem ser irreversíveis, principalmente em razão do caráter finito dos bens ambientais. Dessa maneira, é possível concluir que os problemas ambientais estão intimamente ligados a pautas políticas e econômicas, uma vez que conforme Ulrich Beck (2011, p. 23), "na modernidade tardia, a produção social de riqueza é acompanhada sistematicamente pela produção social de riscos", de modo que as duas variantes coexistem na sociedade e crescem simultaneamente em razão das alegações desenvolvimentistas atreladas a processos de capitalização.

Desse modo, é latente que a distribuição dos riscos mostra-se tendente a acompanhar a desigualdade social que existe no esquema de classes (BECK, 2011, p. 41), revelando assim a perspectiva da vulnerabilidade ambiental e socioambiental. Vulnerabilidade ambiental é definida como sendo "as características e magnitudes de interações ao qual um sistema está exposto, a sensibilidade do sistema e sua capacidade de adaptação a qualquer tipo de alteração que ditam a vulnerabilidade ambiental deste sistema" (AQUINO et al., 2017, p. 16), enquanto vulnerabilidade socioambiental guarda relação “com as mudanças bruscas e significativas que ocorrem na vida do indivíduo ou no grupo que está suscetível a essas mudanças, sendo essas referentes à educação, à saúde, à cultura, ao lazer e ao trabalho" (AQUINO et al., 2017, p. 29).

Dessa maneira, tratar do sistema de recuperação do meio ambiente, em muitas situações, perde sua função finalística, vez que “com isso não se quer dizer que um dano ambiental seja reversível e completamente reparável, uma vez que não se conseguiria restaurar por completo um ecossistema afetado" (FIORILLO, 2019, p. 39). Nessa esteira, diante maior probabilidade de irreversibilidade e irreparabilidade do sistema ambiental ganham protagonismo os princípios da prevenção e precaução do meio ambiente. O princípio da prevenção aplica-se a impactos ambientais já conhecidos, uma vez que a partir da certeza cientifica é possível aferir que determinado empreendimento causará danos ambientais (ANTUNES, 2019, p. 27).

O princípio da precaução, por outro lado, refere-se à intervenção no meio ambiente que não pode acontecer antes de se ter certeza dos prejuízos advindos dessa intervenção. Dessa maneira, precaução, difere-se de prevenção, uma vez que os riscos da atividade são de danos desconhecidos e imprevisíveis, ao passo que para o princípio da prevenção os riscos já são conhecidos pela sociedade e são, portanto, exigidas medidas que previna os riscos que as atividades possam causar. 
Segundo a lei de biodiversidade da Costa Rica, o princípio da precaução pode ser entendido como "princípio in dubio pro ambiente" (MACHADO, 2005, p. 82). É relevante constar que no Brasil o STJ vem também adotando o princípio hermenêutico, chamado de principio in dubio pro natura, ampliando, assim, a proteção da tutela ambiental. Buscando concretizar os princípios supramencionados, a legislação brasileira traz um aparato de mecanismos que se debruçam sobre a ideia de prevenção e precaução do sistema ambiental, um desses instrumentos é o licenciamento ambiental, foco dessa pesquisa e sustentado por Antunes (2019, p. 27) como um instrumento apto garantir a prevenção dos danos.

No processo de licenciamento as três principais licenças expedidas, conforme se extrai da resolução 237/97, são a licença prévia, a licença de instalação e licença de operação ou funcionamento. De acordo com Antunes (2019, p. 141), cada concessão de licença depende do cumprimento das condicionantes impostas em licença anterior.

O licenciamento ambiental pode ou não vir acompanhado concomitantemente da necessidade de apresentação de estudo prévio de impacto ambiental, o EIA. Esse, segundo a Constituição Federal de 1988, somente será exigido quando a atividade cause significativa degradação ambiental, o que conforme explica Fiorillo, (2019, p. 225) “o EIA/RIMA nem sempre é obrigatório, porquanto o próprio texto constitucional condiciona a existência desse instrumento às obras e atividades potencialmente causadoras de significativa degradação ambiental (art. 225, § 10, IV) (...)".

A licença prévia aprova a localização do projeto e atesta a viabilidade ambiental, elencando diversas condicionantes que serão exigidas para a próxima licença. Segundo Antunes (2019, p. 143), a licença prévia é a licença preliminar, que aprovará a localização do empreendimento e atestará a viabilidade ambiental. Trata-se de uma licença menos complexa que as demais, porém não menos importante, pois o que terá que ser objeto da sua análise é o aspecto locacional (macrolocalização) e os seus aspectos mais amplos e específicos serão detalhados e verificados profundamente após o cumprimento das condicionantes impostas e os estudos de impacto ambiental cobrados para a concessão das próximas licenças. Ainda,

(...) para concessão da Licença Prévia basta que os esclarecimentos porventura solicitados sobre os estudos apresentados sejam considerados satisfatórios pelo órgão licenciador, pois nesse momento do procedimento de licenciamento são estabelecidos os requisitos básicos e as condicionantes a serem atendidas nas próximas fases de implementação do empreendimento" (ANTUNES, 2019, p. 143).

A licença de instalação, por sua vez, conforme preceitua o artigo 8, II, da Resolução do Conama no 237 (1997), “autoriza a instalação do empreendimento ou atividade de acordo com as especificações constantes dos planos, programas e projetos aprovados, incluindo as medidas de controle ambiental e demais condicionantes, da qual constituem motivo determinante". Assim sendo, a licença de instalação é o que abre espaço para se edificar o projeto, materializando as condicionantes impostas na licença anterior. 
Contudo, também aqui terá novas condicionantes a serem implementadas na próxima fase, qual seja a licença de operação. Somente depois de cumpridas as condicionantes anteriores é que se autoriza, efetivamente, a operação da atividade ou empreendimento, observadas as condicionantes determinadas para a operação propriamente dita.

O artigo 10 da resolução do Conama $n^{\circ}$ 237/97 determina todo o procedimento do licenciamento até chegar ao objetivo final, qual seja, a expedição da licença ambiental para o empreendimento ou atividade realizada. Durante o processo de licenciamento e as expedições das licenças, é possível que seja cobrado do empreendedor estudos prévio de impacto ambiental. Esses estudos se prestarão para identificação e demonstração, por meio de pesquisas de campo, revisão da literatura e todos os estudos ambientais decorrentes, o quanto a atividade ou empreendimento impactarão o meio ambiente, trazendo também medidas mitigatórias ou compensatórias.

O EIA, previsto na resolução $n^{\circ} 1 / 86$ do CONAMA, tem por objetivo, ao menos primordialmente, a análise dos impactos antrópicos produzidos ao meio ambiente, aqueles que advêm da contribuição humana como causadora. Assim, o EIA/RIMA, conforme Fiorillo (2019, p. 230), "constitui um dos mais importantes instrumentos de proteção do meio ambiente. A sua essência é preventiva e pode compor uma das etapas do licenciamento ambiental".

Da mesma maneira que ocorre com o licenciamento ambiental, o EIA também é um instrumento da política nacional do Meio Ambiente (Lei n. 6.938/81). Nesse sentido, o EIA se propõe a avaliar os custos ambientais advindos do empreendimento em análise, que podem ser negativos e positivos.

O EIA auxiliará o processo de licenciamento ambiental de empreendimentos que causem significativa degradação ambiental, subsidiando a decisão do agente administrativo com elementos e dados técnicos acerca dos danos ambientais potencialmente causados. Dessa maneira, para as atividades que não causem significativa degradação ambiental o EIA não será obrigatório, segundo o expresso no artigo 225 da Constituição Federal. Será considerado como atividade ou empreendimento causador de significativa degradação ambiental o que o órgão ambiental determinar que seja, de acordo com o entendimento de Antunes (2019, p. 166). Em suma, ressaltar que o órgão ambiental não precisa, nem deve estar vinculado ao estudo apresentado.

A importância da existência do RIMA (que nunca se dissocia do EIA) se traduz na possibilidade de participação pública durante o processo de licenciamento, e considerando que não são todas as pessoas que possuem habilidades técnicas suficientes para interpretar os estudos de impacto prévio ambiental, faz-se necessário um documento que possibilite a leitura dinâmica desse documento, o qual somente é possibilitado com o RIMA, que dessa maneira, aparece como um instrumento democrático acerca do conhecimento do impacto que a atividade causara para a população direta ou indiretamente atingida.

Outro ponto de relevância dos estudos de impacto ambientais é o aspecto de estipulação da extensão dos danos que o empreendimento produzirá, devendo ser levado em consideração tanto a 
população que possa vir a ser direta ou indiretamente atingida, respeitando desse modo a vulnerabilidade socioambiental. Apesar de todos os requisitos e percursos que devem ser desenvolvidos no EIA atenção especial tem-se à necessidade de o estudo em análise ser realizado por equipe técnica multidisciplinar, revelando o caráter complexo e aprofundado que o estes estudos ambientais tem, ou ao menos deveriam de ter. A proteção ambiental abrangida pela constituição é ampla e não se restringe apenas na circunscrição natural do espaço, qual seja a proteção do meio ambiente natural, mas também nos diversos meio existentes. Dessa maneira, "o meio ambiente possui conceito multifacetário, dividindo-se em vários aspectos: meio ambiente do trabalho - artificial, natural e cultural" (FIORILLO, 2019, p. 238).

Ao revés do exposto, apesar de toda a proteção legislativa que objetiva a proteção ambiental, os casos que acontecem mundialmente, e em nível local no Brasil, representam e demonstram, falhas que se encontram na proteção ambiental. Conforme bem colocado, "descendo do plano ideal ao plano real, uma coisa é falar dos direitos do homem, direitos sempre novos e cada vez mais extensos, e justifica-los com argumentos convincentes; outra coisa é garantir-lhes uma proteção efetiva" (BOBBIO, 1992, p. 63).

Essa falhas, existentes no sistema de proteção ambiental, ficam evidentes quando nos deparamos com casos de desastres ambientais que poderiam, pelo menos em tese e com a aplicação efetiva das normas ambientais, serem evitados. Um exemplo dessa situação, é o caso de Mariana, que será analisado no próximo capítulo.

\section{O DESASTRE DE MARIANA - MG: UMA ANÁLISE SOBRE O ROMPIMENTO DA BARRAGEM DE FUNDÃO}

Minas Gerais, desde o período colonial, foi conhecida pelo próspero solo, o qual possui uma grande diversidade de minerais. A exploração mineral do solo mineiro remete, dessa maneira, há décadas atrás, consagrando o estado como um estado essencialmente extrativista. Ademais, (in) diretamente estreitou-se a relação de dependência econômica do Brasil com o setor mineral (MANSUR; WANDERLEY; PINTO, 2016, p. 42). Do mesmo modo, aprofundou-se a relação de dependência entre a população ao entorno de cidades minerárias e as mineradoras.

No Estado de Minas Gerais e Espírito Santo localiza-se a bacia hidrográfica do Rio Doce. Ao longo do rio houve instalação de diversas populações, uma vez que a água era utilizada para diversas funções do dia a dia. Ainda, é notória a necessidade das mineradoras em utilizarem desta mesma água do rio em suas atividades.

Barragens de rejeitos são, segundo a Lei no 12.334/2010, em seu artigo 20, "qualquer estrutura em um curso permanente ou temporário de água para fins de contenção ou acumulação de substâncias líquidas ou de misturas de líquidos e sólidos, compreendendo o barramento e as estruturas 
associadas" (BRASIL, 2010). Há uma intersecção inerente entre as barragens de rejeitos minerários, a própria mineração e os princípios da prevenção e precaução do Direito ambiental, vez que a própria natureza, tanto das barragens de rejeitos quanto da mineração necessitam de um sistema de proteção amplo, pelo risco e insustentabilidade inerentes que estas apresentam.

Entende-se o caráter importante que desempenham essas estruturas para o desenvolvimento da mineração, entretanto, não se tem nelas a única forma de resolver o problema gerado pelos rejeitos minerários, muito menos a forma menos impactante ao meio ambiente. De qualquer forma, embora seja notória a devastação que a atividade minerária enseja trata-se de uma atividade de grande importância até os dias de hoje, sendo que a busca por novas tecnologias de disposição, bem como técnicas de controle e fiscalização mais eficientes podem reduzir o impactos ambientais causados pela mineração (ANTUNES, 2019, p. 821).

À vista disso, apesar do seu caráter econômico, não pode ser dispensado o amparo ambiental necessário às situações que causem impacto ambiental. Diante da dicotomia que é apresentada vislumbram-se consequências práticas dessa desarmonia.

No dia 5 de novembro de 2015, rompeu-se a barragem de rejeitos de Fundão, localizada no município de Mariana. Na mesma área, tinha ainda, a barragem de Germano e Santarém, entretanto a barragem de Fundão era a mais nova dentre as três, com operação em 2008 (SANTOS; WANDERLEY, 2016, p. 108). Todas as referidas barragens são de responsabilidade da mineradora Samarco, controlada pela Vale e pela companhia anglo- australiana BHP Billiton.

Mariana, cidade de Minas Gerais, é formada por diversos distritos. Entre eles, Bento Rodrigues, Paracatu de Baixo e Paracatu de Cima. Esses distritos foram, total ou parcialmente, afetados pelo evento ocorrido na empresa Samarco S/A, em cinco de novembro de 2015. Outros municípios afetados com o rompimento da barragem foram Barra Longa, Rio Doce e Santa Cruz do Escalvado. Nessas cidades, segundo Serra (2018, p. 47), “389 casas foram destruídas e 94 danificadas, deixando 812 pessoas desabrigadas".

Das cidades referidas, mais atenção chamam os subdistritos de Mariana, quais sejam, Bento Rodrigues e Paracatu de Baixo que foram completamente destruídos, bem como o distrito de Barra Longa - Gesteira Velha. Logo após o rompimento da barragem devastar, incialmente e quase que completamente, essas cidades a lama com seu material sólido seguiu o percurso do rio Gualaxo do Norte (SERRA, 2018, p. 37).

Ainda é possível identificar as diversas dimensões da sociedade que foram atingidas para além da ambiental, de maneira que, o rompimento da barragem de Mariana não apenas causou poluição, devastação e danos ambientais, mas também deixou inúmeras vítimas fatais do acidente, assim como prejuízos econômicos a toda a população atingida direta e indiretamente (ANTUNES, 2019, p. 821).

A convergência do rio Gualaxo do Norte com o rio do Carmo, na cidade de Barra Longa, e mais adiante da confluência desses (que juntos formam o rio do Carmo) com o rio Piranga forma o 
rio Doce, que segue pelo estado de Minas e Espirito Santo, só encontrando sua foz ao desembocar no oceano atlântico. De acordo com Serra até chegar à intersecção entre o rio do Carmo e o rio Piranga "a lama extrapolara as calhas dos rios e tivera um impacto destrutivo avassalador nos terrenos às margens" (2018, p. 386).

A usina hidrelétrica conhecida como Candonga conteve 10 milhões de $\mathrm{m}^{3}$ de resíduos que vieram com a lama e assim, e a partir dali o lamaçal manteve- se no leito do rio Doce até alcançar a foz, no Espírito Santo (SERRA, 2018, p. 386). Dessa maneira, desse ponto em diante o "mar de lama" não causou mais devastações em cidades, nem soterramentos e destruição de casas, carros e de qualquer objeto a sua frente. Entretanto, os danos ocasionados pelo rompimento da barragem não se restringiram a estes.

Ao mesmo tempo em que ocorrera a destruição dos subdistritos de Mariana e do distrito de Barra Longa, todas as populações ao entorno do rio e inclusive o próprio rio foi atingido. Compreende-se daí, a magnitude de danos ocorridos pelo rompimento, que não se restringiu somente a Mariana, mas a todo o circuito que percorreu o rio Doce, abarcando dois estados brasileiros. Disso, mostra-se a transfronteiricidade dos danos ambientais, que não respeitam demarcações geográficas ou soberanas, e revelam a necessidade que se tem da efetividade dos princípios da precaução e prevenção, bem como dos instrumentos de proteção ambiental.

Nos distritos mais arrasados, em que houve a ocorrência de desabrigados, principalmente, nos subdistritos de Mariana, Bento Rodrigues e Paracatu de Baixo, a população foi alojada, inicialmente em um ginásio de Mariana e, posteriormente, após a intervenção do Ministério Público as famílias foram alocadas em Hotéis, com as despesas pagas pela da empresa (MANSUR et al., 2016, p. 35).

Infere-se uma relação de dependência no que diz respeito às cidades em que se instalam mineradoras. A grande maioria das cidades que recebem esse tipo de empresa, já possuem desigualdades marcantes e ainda, como um "adicional", ficam inseridas em um contexto de desigualdade ambiental. Assim, convivem com todos os aspectos consequentes da injustiça ambiental no que tange a não distribuição equitativa da poluição em torno dessas empresas.

A população que se organizara ao entorno do rio, utilizava este como meio de sobrevivência ou até mesmo para lazer. Muitos, da pesca tiravam seu sustento e o de sua família, mas também, grande parte da população utilizava a água do rio para o plantio e criação de animais, situação que após o rompimento da barragem, não foi mais possível. Existia uma população de índios no entorno do rio, que consideravam o rio sagrado, tirando dele seus alimentos, faziam seus rituais e passavam às suas gerações suas tradições, mas com a devastação do rio não veem mais no lugar seu lar.

Assim, a lama comprometeu áreas de solos férteis e até poços artesianos que abasteciam alguns habitantes foram contaminados, como se tem o exemplo de Gesteira Nova que, apesar de não ter sido destruída pela lama e rejeitos enfrentou problemas com o abastecimento de água, problema esse generalizado nas cidades que dependiam e captavam água no rio Doce (SERRA, 2018, p. 382). 
A crise hídrica ocorreu tanto em cidades de Minas Gerais, quanto em algumas cidades do Espírito Santo afetando o cotidiano de todas as populações. Segundo Serra (2018, p. 47), “em quinze cidades, houve paralisação temporária de empresas e atividades por falta de água e energia nos setores de mineração, comércio, turismo, agropecuária, pesca e extração de areia".

Entretanto, "mesmo durante um acentuado período de estiagem em 2014, a empresa ampliou o seu consumo de água significativamente, [...]. Neste ano e no ano seguinte, a cidade de Mariana identificou uma redução de 50\% no nível da captação de água da cidade" (MANSUR; WANDERLEY; PINTO, 2016, p. 58). Isto posto, vê-se que já existia uma situação de crise hídrica, antes do rompimento da barragem, e gerada, justamente, pela Samarco e seu modelo de tratamento de resíduos.

Além dos danos socioeconômicos ocorridos, da perda de vidas, da crise hídrica que assolou por um longo período essas populações, atingidas direta ou indiretamente, ainda se tem um dano ambiental de grande monta, qual seja, a destruição do rio Doce e de vários ecossistemas ali presente. Segundo Felippe et al (2016, p. 139), “o mote principal dos impactos e danos ao meio físico está relacionado à degradação dos processos geomorfológicos (dinâmica) e da qualidade ecológica do sistema fluvial”. Por conseguinte, tudo o que foi trazido pela lama, inclusive os minérios que nela estavam presentes se depositaram no fundo do rio causando seu assoreamento. Ainda, os sedimentos trazidos pelo rio contaminaram as águas do Rio Doce, o qual abrigava diversas espécies de fauna e flora, dizimando quase que por completo com as vidas aquáticas presentes no rio (RODRIGUES et al., 2016, p. 172).

Desse modo, o desastre ocorrido devastou o rio, seu fluxo natural, bem como sua estrutura física o que irá mudar a dinâmica de inundações, afetando a população ao longo do rio. A vida aquática do rio Doce, segundo Serra (2018, p. 40), “praticamente não existe mais. O oxigênio não consegue mais se misturar e se associar à água e com isso os animais não conseguem retirar o oxigênio para respirar. Toda a vida aquática, que dependia do oxigênio da água, morreu".

A flora local foi quase que por completo extinta e o desastre atingiu extensas áreas, bem como Áreas de Proteção Permanente (APP) e Unidades de Conservações, por exemplo. Segundo Serra "A área de mata atlântica destruída foi de 240,88 hectares (20,47 \%)" (SERRA, 2018, p. 38).

A fauna atingida, não se restringe somente aos animais aquáticos que o rio abrigava, mas também a todos os animais cuja cadeia alimentar do rio dependia. "O Ibama alertou que o nível de impacto foi tão profundo e perverso ao longo de diversos estratos ecológicos que é impossível se estimar um prazo de retorno da fauna ao local, visando o reequilíbrio das espécies na bacia do rio Doce" (SERRA, 2018, p. 39). Verifica-se nessa passagem um típico exemplo do esvaziamento das medidas compensatórias relacionadas à recuperação do meio ambiente.

De toda a situação exposta, depreende-se a afetação direta aos direito humanos que eventos dessa ordem atingem diretamente, até antes do rompimento da barragem, culminando no Conselho Nacional de Direitos Humanos reconhecendo esse desastre como violador de direitos humanos. Consequentemente, compreende-se a magnitude do dano ocorrido não restrito apenas a Mariana, mas 
a grande parte do estado mineiro e parte do estado do Espírito Santo. De maneira direta, nota-se o quão impactante são barragens, principalmente as de rejeitos, que tem potencial de devastar cidades, pessoas e ecossistemas ambientais inteiros. Assim, necessário faz-se buscar a aplicação eficiente de instrumentos preventivos para antecipar e prevenir eventos como este.

No próximo capítulo o licenciamento realizado na barragem de fundão será analisado, a partir do que orienta a legislação ambiental até aqui demonstrada, contrapondo com o que efetivamente foi realizado no desenrolar do licenciamento da barragem e, ainda, se pode ter ocorrido alguma ligação entre o procedimento realizado e o desastre ocorrido em Mariana.

\section{PROCESSO DE LICENCIAMENTO DA BARRAGEM DE FUNDÃO - MG: POSSI- BILIDADE DE INSUFICIÊNCIA ESTATAL CONCESSÃO DO LICENCIAMENTO AMBIENTAL}

O licenciamento ambiental, revestido de seu caráter preventivo, é um dos instrumentos que no caso de Mariana não foi utilizado de maneira eficiente o suficiente para evitar os danos ocorridos. Segundo Toledo, Ribeiro e Thomé, "as barragens de rejeitos de mineração devem ser tratadas como um exemplo de atividade perigosa, nos termos do artigo $2^{\circ}$ da Convenção de Lugano" (2019, p. 40). Dessa maneira, para a construção das barragens de mineração os empreendedores devem se submeter ao procedimento do licenciamento ambiental, conforme resolução do CONAMA 01/1986, como forma de regularização socioambiental.

Nas últimas décadas, uma das principais críticas alçadas ao procedimento do licenciamento é a do objetivo existente por trás da maneira com a qual é conduzido. O interessante é que em Mariana, apesar da complexidade que existia para o empreendimento de Fundão, o licenciamento dessa barragem foi concedido em tempo recorde (SERRA, 2018, p. 115).

Ao que se observa o vetor político, aliado a governança corporativa dos estados e municípios, ao abrigar o empreendimento em razão, principalmente, do tributo decorrente da instalação das atividades minerárias (CFEM) tem sido fator de grande influência nas decisões tomadas no licenciamento ambiental, uma vez que esses entes públicos estão sempre de acordo a trazer para suas localidades empreendimentos que prometem a geração de empregos, renda e, principalmente previsões das compensações resultantes do licenciamento dos empreendimentos de maior porte (TRENNEPOHL; TRENNEPOHL, 2020, p. 55).

O procedimento do licenciamento ambiental realizado em Mariana, MG, revelou algumas falhas, as quais estão em muitos outros empreendimentos licenciados, e sobre as quais, se existisse mais cautela na atuação dos órgãos ambientais, poderiam ter sido evitadas. Um dos problemas centrais que contribuem para a ineficiente condução dos licenciamentos é o fato que os órgãos ambientais se encontram sucateados, com falta de pessoal e falta de ativo financeiro, o que influi no processo de licenciamento que é realizado. 
Além dos problemas estruturais que os órgãos ambientais enfrentam o governo de maneira contrária ao preceito do desenvolvimento sustentável, incentivou que a quantidade de licenças ambientais expedidas seja bonificada, de acordo com a portaria 216 do Ministério do Meio ambiente, o que põe em cheque a qualidade e enfraquece o objetivo deste instrumento da Política Nacional do Meio Ambiente.

Além disso, o processo de licenciamento encontra-se com outras falhas em seu trâmite que precisariam ser melhores abordadas pela lei, e muitas delas se mostraram presente no caso de Mariana, principalmente a partir da investigação feita pelo Ministério Público de Minas Gerais - MPMG e Ministério Público Federal - MPF. Segundo Serra e a partir das investigações do MPF “todas as apurações apontaram que a causa imediata do rompimento foi a liquefação dos rejeitos" (SERRA, 2018, p. 125). A liquefação dos rejeitos decorre da saturação de água no solo e aumento de pressões nesses rejeitos (SERRA, 2018, p. 128). Esse fenômeno, segundo Araújo (2006, p. 14), ocorre de maneira mais propícia em barragens alteadas pelo método a montante uma vez que esse método apresenta menos segurança em sua construção e os alteamentos são realizados sobre materiais previamente depositados e não consolidados.

Uma das causas que contribuíram o fenômeno da liquefação na barragem foi o fato de o projeto inicial de construção dos drenos da barragem ter sido alterado, uma vez que segundo investigados confirmaram que a Samarco, para a construção dos drenos utilizou material mais barato (SERRA, 2018, p. 131). Além disso, com o aumento da produção eram realizados mais alteamentos, o que é importante ressaltar que no projeto licenciado Fundão teria mais capacidade de contenção de rejeitos do que a quantidade que existia na barragem no dia de sua ruptura (SERRA, 2018, p. 96). Essa situação revela certa incongruência nos estudos de impacto ambientais realizados, e omissão aos eventuais danos que poderiam vir a ocorrer com uma estrutura de tamanho porte licenciada, principalmente os danos na bacia hidrográfica que abrigava a barragem, e na população a jusante.

A "economia" realizada pela empresa pode ser explicada a partir do aumento da exploração da mina e consequentemente maior produção de rejeitos, o que ocorre principalmente em períodos de queda nos preços das commodities. De maneira tal que, "a doutrina chega a verificar uma correlação entre a intensidade da atividade de mineração e o aumento do número de acidentes com barragens de rejeitos depois do fim do ápice de exploração” (TOLEDO; RIBEIRO; THOMÉ, 2019, p. 137).

Apesar de essa ser uma das principais causas que contribuíram para o rompimento é possível elencar outras relacionadas ao procedimento de licenciamento realizado, bem como as falhas no monitoramento, a despeito dessa última não ser foco desse trabalho ${ }^{5}$. Além das diversas mudanças

\footnotetext{
5 Importante ressaltar que, em divulgação do Relatório de segurança de barragens de 2019 (ANA, 2020), "houve aumento na quantidade de barragens que preocupam os órgãos fiscalizadores - 26 deles listaram um total de 156 barragens críticas em 22 estados. A verificação in loco do estado de conservação das barragens é o método mais utilizado pelos fiscalizadores na determinação dessa listagem. Diferentemente do apontado no RSB anterior, a maior parte dessas barragens identificadas como críticas $(63 \%)$ pertence a empreendedores privados.
} 
ocorridas no projeto de construção da barragem, que acabaram contribuindo para o rompimento, é importante compreender as várias lacunas ocorridas logo no início do procedimento do licenciamento ambiental, uma vez que várias condicionantes foram descumpridas, conforme relatado em investigação do Ministério Público e Polícia Federal.

Segundo a pesquisa de Serra (2018, p. 100), a partir das investigações realizadas, foi revelado que como condicionantes para obtenção da licença de instalação, entre outras, a empresa teria que fazer um projeto que assegurasse a estabilidade de uma pilha de estéril da Vale que encontrava-se próxima a barragem de Fundão e que poderia interferir na estabidade e segurança da barragem de Fundão (como de fato ficou comprovado) e apresentar o projeto executivo da barragem, sendo este último o estudo que atesta a segurança de qualquer barragem. A primeira condicionante refere-se a distância mínima para evitar interferência entre a barragem de Fundão e a pilha de estéril da Vale, bem como assegurar a estabilidade da pilha da Vale, e a segunda refere-se ao plano estrutural da barragem e ao componente que irá depositar.

Entretanto, “o COPAM confirmou a LI, apesar do não cumprimento de duas condicionantes fundamentais" (SERRA, 2018, p. 102). Essa situação além de ser contrária ao que dispõem a legislação ambiental também deixa em risco a estrutura da própria barragem, uma vez que documentos essenciais à sua estrutura não foram apresentados. Para a concessão da licença de operação era esperado o cumprimento de uma condicionante de suma importância em empreendimentos que gerem situação de perigo à sociedade, qual seja, o plano de contingência. De qualquer maneira, o órgão ambiental entendeu que a barragem poderia funcionar, e então foi concedido o licenciamento de Fundão.

Toledo, Ribeiro e Thomé (2019, p. 99), ao tratarem do tema das condicionantes no licenciamento ambiental concluem o que a lei já traz de maneira expressa: "Nos termos do artigo $8^{\circ}$ da resolução do Conama 237/1997, a licença de Operação somente será concedida após a verificação do cumprimento das exigências previstas nas licenças preliminares".

As diversas alterações que a barragem sofreu, e a falta de documentação a cerca de sua estabilidade, muitas das quais deveriam ter sido apresentadas durante o licenciamento, propiciaram um ambiente sem informações confiáveis e/ou informações totalmente desatualizadas em relação à situação da barragem. Um exemplo disso é a falta de atualização da Carta de Risco da barragem.

Ainda, em relação ao EIA/RIMA apresentado, o documento apresenta incongruências com a real situação que se encontrava a barragem e o alcance que eventual dano poderia ocasionar. Ademais, uma importante sugestão contida no EIA/RIMA da barragem efetivamente não foi cumprida, qual seja a execução de um plano de participação da comunidade que eventualmente pudesse vir a ser atingida pelo empreendimento (SERRA, 2018, p. 99), situação essa que contribuiu para as 19 mortes ocorridas.

Esse programa jamais ocorreu na comunidade a jusante da barragem, inocorrência essa demonstrada a partir do fato de que "a empresa nem sequer tinha um plano de emergência com medidas 
básicas, como sirenes nos povoados situados nos vales abaixo, a jusante, da barragem. Fundão ficava apenas 6 quilômetros da primeira comunidade atingida, Bento Rodrigues” (SERRA, 2018, p. 78).

Ademais, EIA/RIMA apresentado também foi ineficaz a medida que considerou que não estavam "fixados, nas áreas lindeiras ao empreendimento, agrupamentos populacionais ou comunidades, fator que otimiza sua inserção socioambiental" (SERRA, 2018, p. 98). Ainda, segundo entrevista de Serra com José Carlos Carvalho, secretário estadual de Meio Ambiente de Minas Gerais, em relação ao licenciamento, mais precisamente aos estudos de impacto ambientais produzidos, este conclui que os estudos foram realizados de forma insuficiente, uma vez que não analisaram os impactos e danos sinergéticos que poderiam ocorrer com a ruptura da barragem, restringindo a área afetada somente à Bento Rodrigues (SERRA, 2018, p. 111).

Os estudos realizados foram falhos e pouco abrangentes, contrariando, inclusive, o princípio da prevenção ambiental. Esse conjunto de circunstâncias não foi verificado ou foi negligenciado no licenciamento ambiental, fato é que a partir desses estudos a viabilidade ambiental da barragem foi assegurada pelos órgãos ambientais responsáveis à medida que a concessão da licença prévia atesta a viabilidade ambiental com base no EIA/RIMA (TOLEDO; RIBEIRO; THOMÉ, 2019, p. 101).

É possível identificar que o EIA/RIMA foi tão falho que praticamente inexistente de eficácia e utilidade no licenciamento da barragem de Fundão. A área de influência direta e indireta da barragem foi mal delimitada, como visto anteriormente, bem como a intensidade dos impactos eventuais, que no caso ocorreram e persistem até os dias de hoje. Esses aspectos, entretanto, legalmente deveriam ser exigidos no licenciamento ambiental realizado, conforme o disposto nos $\operatorname{artigos} 5^{\circ}$ e $6^{\circ}$ da Resolução 1/86 do CONAMA.

Além do mais, importante destacar o fato de que a maioria dos empreendimentos minerários não se propõe a apresentar alternativas tecnológicas diversas das barragens para a contenção dos rejeitos minerários, apresentação essa também exigida pela lei. Dessa forma, conforme aduzem Toledo, Ribeiro e Thomé (2019, p. 17) o setor minerário tem, cada vez mais persistido na adoção das barragens de rejeitos como únicas alternativas para o tratamento dos resíduos.

Isto posto, conclui-se pela falta de eficiência desse instrumento, qual seja o licenciamento ambiental, em razão da ineficiência e insuficiência do controle estatal, no que tange a análise ambiental. O que se demonstra do caso concreto é o que a doutrina vem a corroborar, no que tange ao licenciamento ambiental "na prática, os projetos não passam por um planejamento consistente em razão da agilidade pretendida" (TOLEDO; RIBEIRO; THOMÉ, 2019, p. 119). Ainda, quanto ao licenciamento ambiental este carece de congruência e análise sinérgica de todos os aspectos envolvidos no procedimento.

\section{CONCLUSÃO}

O trabalho teve como intuito analisar como que o procedimento de licenciamento ambiental deve ser realizado de acordo com a legislação ambiental e como que efetivamente foi realizado na 
prática. A pergunta central da pesquisa foi a de que se no caso Mariana- MG seria possível alegar a possibilidade da insuficiência estatal na concessão do licenciamento frente ao rompimento ocorrido em 05 de novembro de 2015? Sintetizando, o licenciamento concedido à barragem de Fundão contribuiu, sim, para a ocorrência de seu rompimento.

Com base na previsão da legislação brasileira a respeito do licenciamento ambiental, evidenciado no primeiro capítulo, é possível denotar que quando confrontado com os dados técnicos obtidos na investigação para a apuração do inquérito da ação civil pública, relatados no terceiro capítulo, realmente houve omissões e negligências na condução do procedimento pelo órgão estatal ambiental responsável.

Durante o licenciamento houve um conjunto de fatores que foram determinantes para a ocorrência do rompimento, entre os quais, a mudança do projeto licenciado e condicionantes não cumpridas, as quais foram explicadas no terceiro capítulo. A maneira com que foi conduzido o licenciamento ambiental foi insuficiente para, ao menos, garantir que os danos ocorridos em cidades mineiras e capixabas ocorressem. A extensão dos danos decorrentes do rompimento da barragem foi perpassada no segundo capítulo deste trabalho, no qual é possível analisar os rasos estudos de impactos ambientais realizados.

Os estudos de impacto ambiental realizados também carecem de informações imprescindíveis ou, ainda, são realizados com informações incompletas acerca da declaração de viabilidade dos empreendimentos licenciados. É preciso mudar a perspectiva e o modelo filosófico por detrás do procedimento do licenciamento ambiental, e utilizá-lo de maneira a se preocupar mais com o meio ambiente antes da aprovação do empreendimento econômico.

Por óbvio não se quer embargar obras e sustar o desenvolvimento econômico do país, mas sim melhorá-lo, de maneira com que grandes empreendimentos, muitos dos quais de empresas transnacionais, não acabem com a riqueza ambiental do Brasil. Desenvolvimento econômico e sustentabilidade ambiental podem "andar juntos" efetivamente. Diante de todo o exposto neste trabalho é possível chegar à conclusão que o licenciamento realizado em barragens de rejeitos gerados pela atividade minerária deixa muito a desejar, principalmente considerando-se o elevado número de acidentes por ano, que ocorre com barragens de rejeitos de mineração.

Um licenciamento expedido de forma apressada, falha e omissa demonstrou, na prática, a extensão dos danos socioambientais que pode ocasionar, evidenciando o quanto ainda é necessário muito empenho e esforço do poder público para mudar a atual situação da análise do procedimento para o licenciamento ambiental, em todas as suas fases. Com a elevação dos preços de exportações de commodities as mineradoras muitas vezes conseguem acelerar a libração de licenças em velocidade que enseja margem para levantamento de dúvidas, principalmente quanto à análise do licenciamento realizado, e os estudos ambientais apresentados. Contudo, em fases de desaquecimento da economia esses empreendimentos exploram até o limite dessas estruturas, quais sejam, as barragens de rejeitos, uma vez que o aumento do minério extraído está diretamente ligado ao aumento dos rejeitos produzidos pelo processo de mineração. 
Há inúmeros relatos de rompimento de barragens, uns mais divulgados do que outros. $\mathrm{O}$ desastre de Mariana, por exemplo, foi amplamente noticiada em razão da extensão de danos que causou. Não obstante a extensão do dano é possível afirmar que barragens são em sua maioria de segurança duvidosa tanto para a população de seu entorno, quanto às bacias hidrográficas próximas, colocando em risco todo o ecossistema. Ademais, essas estruturas (barragens de rejeito) tornam-se, após seu exaurimento, paisagens permanentes no meio ambiente em que se inserem, persistindo, assim, os danos e riscos ambientais, necessitando, deste modo, de manutenção para contínua.

$\mathrm{O}$ caso do rompimento da barragem de Fundão demostra de maneira definitiva a necessidade de proposições de alternativas tecnológicas mais eficientes para tratar dos rejeitos da mineração, como por exemplo, as tecnologias de disposição a seco de rejeitos entre outras, já disponíveis no mercado. O método de tratamento dos resíduos também relaciona-se com um dos principais problemas existentes durante a elaboração do licenciamento ambiental, qual seja, a prevalência das preocupações econômicas em detrimento das ambientais.

Sendo assim, o licenciamento tem por objetivo primordial a proteção socioambiental, e é essa proteção que deve ser priorizada durante as expedições das licenças para a liberação do empreendimento. Por isso, esse procedimento necessita de um novo marco principiológico no setor público que o gerencia, objetivando evitar ao máximo a ocorrência de desastres para que efetivamente os princípios protecionistas e preventivos que a lei e o cenário internacional ambiental impõem, sejam efetivamente colocadas em prática, em respeito às gerações futuras.

\section{REFERÊNCIAS}

ANA - Agência Nacional de Águas e Saneamento Básico (Brasil). Relatório de segurança de barragens 2019. Brasília: ANA, 2020.

ARAUJO, Cecília Bhering de. Contribuição Ao Estudo Do Comportamento De Barragens De Rejeito De Mineração De Ferro. Dissertação (Doutorado) - Curso de Engenharia, Universidade Federal do Rio de Janeiro, Rio de Janeiro, 2006. Disponível em: https://bit.ly/3jcuvCt. Acesso em: 28 out. 2020.

ANTUNES, Paulo de Bessa. Direito Ambiental. Rio de Janeiro: Atlas 2019. Recurso online

AQUINO, Afonso Rodrigues de; LANGE, Camila Neves; LIMA, Clarice Maria de; AMORIM, et al. Vulnerabilidade Ambiental. AQUINO, Afonso Rodrigues de; PALETTA, Francisco Carlos; ALMEIDA, Josimar Ribeiro de. (org). São Paulo, SP: Edgard Blücher Ltda, 2017. 
BASTOS, Anna Christina Saramago; FREITAS, Antonio Carlos de. Agentes e Processos De Interferência, Degradação E Dano Ambiental. In: CUNHA, Sandra Baptista da; GUERRA, Antonio José Teixeira (org.). AVALIAÇÃO E PERÍCIA AMBIENTAL. Rio de Janeiro: Bertrand Brasil, 2006. p. 1-284.

BECK, Ulrich. Sociedade De Risco: Rumo a uma outra modernidade. São Paulo, SP: EDITORA 34 (tradução) 2011.

BOBBIO, Norberto. A Era Dos Direitos. Rio de Janeiro: Campus, 1992.

BRASIL. Lei 6.938, De 31 De Agosto De 1981. Brasília, DF: Presidente da República. Disponível em: https://bit.ly/3peA5YO. Acesso em: 17 ago. 2020.

BRASIL. Lei 12.334, De 20 De Setembro De 2010. Brasília, DF: Presidente da República. Disponível em: https://bit.ly/3BUdvrJ. Acesso em: 17 ago. 2020.

CAMPOS, Bárbara Pincowsca Cardoso; MUCHAGATA, Márcia. Direitos Humanos E Meio Ambiente: Avanços E Contradições Do Modelo De Desenvolvimento Sustentável Brasileiro E A Agenda Internacional. In: TRINDADE, Antônio Augusto Cançado; LEAL, César Barros (org.). Direitos Humanos e Meio Ambiente. Fortaleza: Expressão Gráfica e Editora, 2017. p. 1-356.

CRUZ, Paulo Márcio; BODNAR, Zenildo. Globalização, Transnacionalidade E Sustentabilidade. Itajaí: Univali, 2012. Disponível em: http://www.univali.br/ppcj/ebook. Acesso em: 20 de maio 2020.

FELIPPE, Miguel Fernandes; COSTA, Alfredo; JÚNIOR, Roberto Franco; et al. Acabou- Se O Que Era Doce: Notas Geográficas Sobre A Construção De Um Desastre Ambiental. In: MILANEZ, Bruno; LOSEKANN, Cristiana (org.). Desastre no vale do rio doce: Antecedentes, impactos e ações sobre a destruição. Rio de Janeiro: Folio Digital: Letra e Imagem, 2016. cap. 3, p. 125- 157.

FIORILlO, Celso Antonio Pacheco. Curso de Direito Ambiental Brasileiro. São Paulo: Saraiva. 2019. Recurso online.

MANSUR, Maíra Sertã; WANDERLEY, Luiz Jardim; PINTO, Raquel Giffoni. Avaliação dos Antecedentes Econômicos, Sociais e Institucionais do Rompimento da Barragem de Rejeito da Samarco/ Vale/Bhp em Mariana (Mg). In: MILANEZ, Bruno; LOSEKANN, Cristiana (org.). Desastre no Vale do Rio Doce: Antecedentes, impactos e ações sobre a destruição. Rio de Janeiro: Folio Digital: Letra e Imagem, 2016. cap. 1, p. 39- 87. 
MACHADO, P. A. L. Direito Ambiental Brasileiro. 13. ed. rev. atual. e ampl. São Paulo: Malheiros, 2005.

MANSUR, Maíra Sertã; WANDERLEY, Luiz Jardim; MILANEZ, Bruno; et al. Antes Fosse Mais Leve A Carga: Introdução Aos Argumentos E Recomendações Referente Ao Desastre Da Samarco/ Vale/Bhp Billiton. In: Zonta, Marcio; Trocate, Charles (Org.). Antes Fosse Mais Leve A Carga: Reflexões Sobre O Desastre Da Samarco/Vale / Bhp Billiton. 1. ed. Marabá, PA: IGuana, 2016. v. 2, cap. 1 , p. 17-49.

ONU. A ONU e o meio ambiente. Disponível em: https://bit.ly/3vlMs6n. Acesso em: 20 maio 2021.

RESOLUÇÃO CONAMA No 237, de 19 de dezembro de 1997. Disponível em: https://bit.ly/3aKnp3r. Acesso em: 20 maio 2021.

RODRIGUES, Daiana Elias; CRUZ, Marina Abreu Corradi; DIAS, Ana Paula de Melo; et al. Algumas Análises Sobre Os Impactos À Saúde Do Desastre Em Mariana (Mg). In: MILANEZ, Bruno; LOSEKANN, Cristiana (org.). Desastre no Vale do Rio Doce: Antecedentes, impactos e ações sobre a destruição. Rio de Janeiro: Folio Digital: Letra e Imagem, 2016. cap. 4, p. 163- 193.

SANTOS, Rodrigo Salles Pereira dos; WANDERLEY, Luiz Jardim. Dependência De Barragem, Alternativas Tecnológicas E A Inação Do Estado: Repercussões Sobre O Monitoramento De Barragens E O Licenciamento Do Fundão. In: ZONTA, MARCIO; TROCATE, CHARLES (org.). Antes Fosse Mais Leve a Carga: Reflexões sobre o desastre da Samarco/ Vale / BHP Billiton. 1. ed. Marabá, PA: IGuana, 2016. v. 2, cap. 3, p. 87-137.

SERRA, Cristina. Tragédia Em Mariana: A História do Maior Desastre Ambiental do Brasil. 1. ed. Rio de Janeiro: Record, 2018. E-book, Kindle.

SILVA, Jarbas Vieira da; ANDRADE, Maria Júlia Gomes. Introdução. In: MILANEZ, Bruno; LOSEKANN, Cristiana (org.). Desastre no Vale do Rio Doce: Antecedentes, impactos e ações sobre a destruição. Rio de Janeiro: Folio Digital: Letra e Imagem, 2016. Introdução, p. 11- 23.

TOLEDO, André de Paiva; RIBEIRO, José Cláudio Junqueira; THOMÉ, Romeu. Acidentes com Barragens de Rejeitos da Mineração e o Princípio da Prevenção: de Trento (Itália) a Mariana (Brasil). 2. ed. atual. Rio de Janeiro: Lumen Juris, 2019. 
TYBUSCH, Francielle Benini Agne. Vidas Deslocadas: O caso Mariana-MG como modelo brasileiro para aplicação do Direito Dos Desastres. Curitiba: Íthala, 2019.

TRENNEPOHL, Curt; TRENNEPOHL, Terence. Licenciamento Ambiental. 8. ed. atual. São Paulo: Thomson Rauters, 2020. 
